There was a wide scatter from this formula; signals have been received from an $80-\mathrm{lb}$. shot at $190 \mathrm{~km}$.

In making measurements with two ships, the splitprofile type of record was most often taken; the firing ship drops charges continuously and steers an approximately straight course, passing the stationary recording ship and its hydrophones at the middle of its run. The reverse profile technique was also used occasionally; but owing to drift and navigational difficulties the full value of a reverse profile was never completely realized. For the interpretation of the seismic refraction data, the assumptions of constant-velocity layers, the velocity of which successively increased with depth, wore used. In addition to the topmost layers of sediment, three distinct velocity layers were observed having velocities of $4 \cdot 0-6 \cdot 0,6 \cdot 5-7 \cdot 0$ and $8-8 \cdot 5 \mathrm{~km}$. $/ \mathrm{sec}$., respectively. Changes in these velocities in a lateral direction were observed ; but whether these are always real is uncertain. The velocity in the upper sediments was not determined by refraction; but a few reflexion measurements gave an average at $2 \cdot 15 \mathrm{~km}$. $/ \mathrm{sec}$.

Dr. Raitt presented a slide showing the thickness of the crust defined by the depth at which the velocity reaches $8 \mathrm{~km}$. $/ \mathrm{sec}$. as found by several workers on the continents and by his work in the Pacific Ocean. The mean thickness for the Pacific Ocean is about $6 \mathrm{~km}$., which contrasts with the $30 \mathrm{~km}$. for the continents.

Questioned on the dependence of arrival time on frequency, Dr. Raitt said that only at short distance was it possible to observe waves of different frequency travelling over the same path. In these cases, no dependence on frequency was observed. When asked by the chairman if he had any views on the composition of the layer below the unconsolidated sediments, Dr. Raitt said that it is in doubt whether they are volcanic or sedimentary. The answer to this problem would tell us much about the history of the oceans. If the $4 \cdot 0-6 \cdot 0 \mathrm{~km}$. $/ \mathrm{sec}$. layer is lithified sediment, the oceans are probably very much older than would be expected if the layer were igneous.

Dr. S. Wyrobek (British Petroleum Co.), who read the third paper, said the refraction method has been used in some areas to give a fairly comprehensive picture of the variation of velocity in both the lateral and vertical directions and to reveal subsurface structural features. It is known that the method is most successful where velocity contrasts are pronounced, but it has been perfected to the extent of delineating layers where the velocity contrast is less than $2,000 \mathrm{ft}$. $/ \mathrm{sec}$.

The guiding principlo in deciding the disposition of geophones and shots is to cover continuously all the important refractors in the area and especially the shallow refractors, since these greatly influence the shape of the decper layers. A refraction line consists of several spreads. Each spread may have twentyfour geophones 250-I,000 ft. apart and several main shot points outside the spread at distances of 5,000 $10,000 \mathrm{ft}$. At each geophone station or every alternate one, smaller shots are fired, which elucidate the weathered layer and any low-velocity layers. Continuous time profiles are obtained in both directions of shooting, and these are used for obtaining half-intercept time values and hence the values of the refracting velocities and their lateral variations. By the method of interpretation used, individual refractors are discriminated by ensuring that the reciprocal times are equal, that the intercept times match in each direction of shooting, and that both the direct and reverse tirne profiles match the halfintercept time values if one deals with the same refractor.

The aim of the method is first to convert the time-distance curve into a time section, that is, into a section in which the vertical scale gives the delaytime of a point on the refractor below the datum; this is achieved by producing the so-called halfintercept time profiles. From the latter, by using information obtained from well surveys or assuming the seismic velocities determined for the upper refractors to be uniform in a vertical direction, or introducing a velocity distribution characteristic of the area, a depth profile for each refractor is easily obtained.

Mr. D. R. Brown asked what velocity variations and dips could be encountered before the method broke down, to which Dr. Wyrobek replied that the complications would appear where lateral variation of velocity along a refractor approached the variation in the vertical direction. The method has proved satisfactory in areas of dips up to $8^{\circ}$. It will be published in a subsequent number of the Geophysical Prospecting Journal of the European Association of Exploration Geophysicists.

1 Peterson, R. A., Fillippone, W. R., and Coker, F. B., Geophysies, 20, No. 3, 516 (1955).
.

\section{ELECTRICAL EQUIPMENT OF AIRCRAFT}

$\mathrm{T}$ HE convention, as a means of bringing to a focus widely scattered knowledge of a particular subject, has gained a great deal of popularity in recent years, and that on "Electrical Equipment of Aircraft", held in London at the Institution of Electrical Engineers during May 2-4, proved to be no exception; the accommodation of the lecture hall of the Institution was strained to the utmost, and additional chairs were placed wherever possible. The chair at the opening session was taken by the president of the Institution, Sir George $H$. Nelson, and the proceedings began with a short address by the Minister of Supply, Mr. R. Maudling.

Mr. G. R. Edwards, general manager and chief engineer (aircraft) of Vickers-Armstrongs, Ltd., followed with a most entertaining talk, in which his humorous sallies provided some light relief for the serious matter of his address, which was the problem of the aircraft designer, wishing and indeed compelled to uso electricity to an ever-increasing extent for a multitude of purposes in connexion with the functioning of the aircraft, and yet faced with the reduction of useful load-carrying ability involved in the weight and drag of electrical equipment and its cooling auxiliaries. The only electrical equipment on the earliest aircraft was a magneto generator to supply the ignition system, and this was both light and reliable. Modern large civil and military aircraft are equipped with about $150 \mathrm{~kW}$. of electrical power and, with developments likely in the near future, the power provided may rise to $400 \mathrm{~kW}$., or even, according to some estimates, to $700 \mathrm{~kW}$. The weight of the equipment, with the additional fuel required to drive it, is of the order of 3 per cent of the total aircraft weight. If the pay-load of a eivil aircraft is 10 per cent of the total aircraft weight, the electrical equipment reduces the pay-load by one-quarter, and the importance of saving weight is apparent. 
Important as it is to save weight, it is still more important to achieve reliability. Moreover, the increase in speed and flying height of modern aircraft introduces new problems of cooling and brushwear which are generally adverse to saving weight. The designer is at a disadvantage compared to his land-based colleagues in every respect except cost, which he may largely ignore if a saving in weight may be achieved by the use of costly materials or special apparatus.

Nineteen papers* were presented at the convention covering the uses of electrical power, the means to obtain it and the methods and equipment necessary to obtain reliability. The last session was devoted to a discussion of the problems of installation and maintenance, which often influence the choice of equipment for a particular aircraft.

The importance of weight-saving would appear to justify the design of the electrical equipment as a single unit, each element being planned to give minimum total weight to the equipment rather than to have minimum weight itself. This ideal has not yet been achieved, and the choice of supply system, for example, is often governed more by the availability of consuming apparatus of a given design than by a rigid assessment of the optimum system for minimum weight.

The most popular generating systems at present are 28 volts and 112 volts d.c., and 200 volts three. phase a.c. with 115 volts between line and neutral. The frequency of a.c. supplies may be variable from $200 \mathrm{c} . / \mathrm{s}$. to $500 \mathrm{c} . / \mathrm{s}$. according to engine speed; or generation may be achieved at a fixed frequency of $400 \mathrm{c} / \mathrm{s} ., 1,600 \mathrm{c} . / \mathrm{s}$. or $2,400 \mathrm{c} . / \mathrm{s}$. either by a differential speed drive between the engine and the generator or by a separate power unit. It is unfortunately not practicable to design all consuming apparatus to operate from the same supply system. and, whichever system is adopted, means have to be provided, usually by additional motor generator sets, to provide auxiliary supplies.

The 28-volt d.c. system is popular on account of ease of maintenance and reliability. Fewer cells are required in a standby battery, and heater filaments for this voltage are of adequate section so that they fail less frequently. Transmission losses and the weight of cable required become serious in large aircraft, although this aspect is complicated by the large number of cables the dimensions of which are fixed by considerations of mechanical strength rather than by current-carrying capacity. Aluminium conductors offer the possibility of reduced weight for the same current-carrying capacity, but at the expense of increased volume. It is not always

*S. F. Follett: electrical equipment in aircraft--survey of past and present practice and future trends in design. H. Zeffert: factors in the utilization of electrical power in aircraft. B. J. O'Kane: air craft radio power supplies $\rightarrow$ a survey. J. F. Lewis and E. Lloyd the airworthiness and reliabilty of aircraft electrical systems. A. Ball and R. N. Lake: the medium-voltage d.c. system in aircraft and it application in the "Princess"-class flying boats. P. L. Cronbach rectified-a.c. generating systems in aircraft. P. C. Finucane: constant-frequency a.c. system for aircraft. D. C. Flack : future trends in aircraft clectrical systems. R. G. Woodall, P. J. Daglish and V. A. Higgs: trends in the development of airborne electrical equipment, with particular reference to constant-frequency a.c.
systems. B. Adkins, W. Philipp and A. Hossle : electrical machines systems. B. Adkins, W. Philipp and A. Hossle : electrical machines for aircraft. C. S. Hudson: the cooling of aircraft electrical equipment K. J. Payne: electrical characteristics and protection of aircraft power systems. W. G. Bourne and A. Grieve aircraft switchgear cables $\mathrm{C}$. W. Cooper : the development of voltage and frequency regulators for aircraft electrical systems. G. A. Earwicker: aircraft batteries and their behaviour on constant-potential charge. A. H. M. Arnold and L. H. Ford : d.c. circuit interruption and arc characteristic at low air pressures. I. A. Mossop and F. D. Gill: the current and voltage relationships of a stable d.c. arc between copper and silve electrodes in air at $1-760 \mathrm{~mm}$. of mercury. N. C. Adcock and A. W. Ford: excitation systems for a.c. aircraft generatiors . practicable to accommodate the larger aluminium cable.

The 112-volt d.c. system generally yields a reduction of weight both of the generators and of the cables, although the reduction of weight is not as striking as might be expected, since the additional insulation increases the weight of cables of minimum section.

The a.c. systems gain flexibility from the use of transformers; but the transformer weight is not economically used in the variable-frequency system. Moreover, some constant-frequency supplies are necessary for some of the consuming apparatus, and this has to be provided by motor generators. These additions of weight have to be balanced against the reduction achieved by a direct engine drive. The constant-speed hydro-mechanical drive or the auxiliary power unit to give constant frequency is gaining in popularity.

A serious problem for high-altitude flying is brush wear. This problem is less serious with slip-rings than with commutators, so that a.c. supplies have an advantage in this case. The development of satisfactory silicon rectifiers which can be operated at higher temperatures than germanium rectifiers makes possible the design of brushless alternators and also enables d.c. supplies to be obtained with a reasonable weight penalty from a.c. generators.

The most popular frequency system is $400 \mathrm{c} / \mathrm{s}$. Transformer weights are reduced at the higher frequencies; but this advantage is counterbalanced to some extent by increased eddy-current losses in cables. The higher frequencies may be essential for some consuming apparatus.

The cooling of electrical equipment is a major problem, especially at high altitudes and speeds. Designs of minimum weight of electrical equipment tend to be inefficient, and this increases the weight of cooling equipment and the drag it exerts on the aircraft. In many cases, it is preferable to increase the efficiency of the electrical equipment at the expense of its weight in order to reduce the cooling problem. So far as practicable, engine fuel should be used for absorbing heat : additional cooling is usually air cooling, either by natural convection and radia. tion, or by blast cooling. Limits are set by ambient air temperature which rises with the speed of the aircraft on account of adiabatic compression at the intakes. When the ambient air temperature is higher than that of the electrical equipment, refrigeration must be employed in order to dissipate the heat.

Striking developments of batteries have taken place in the search for weight reductions. The leadacid battery has been reduced about 40 per cent in woight by improved materials and construction, while the newly developed nickel-cadmium battery and zinc-silver oxide battery give a better discharge performance than the lead-acid battery.

Finally, the smooth functioning and reliability of the equipment is vitally dependent on satisfactory frequency and voltage regulators and on a good protection system, including adequate switchgear. Switch performance is generally adversely affected at high altitudes by the change in the arc characteristics; although research has shown that this deterioration is not as severe as early experiments had suggested, it is clear that alternating currents are likely to be more easily interrupted than direct currents, and this is a further argument in favour of the a.c. system. 
Most aspects of aircraft electrical equipment were thoroughly covered by the papers presented, and these, together with the discussions on them, should provide a useful work of reference for those concerned with the design or utilization of such equipment. An interesting point made was concerned with the adverse effect of standardization on the weight of electrical equipment, and a plea was entered for an increase in the number of standard sizes in order to reduce the weight penalty.

\section{MARINE BIOLOGY}

\section{SYMPOSIUM AT THE SCRIPPS INSTITUTION}

A SYMPOSIUM on "Perspectives in Marin A Biology" was held in the Scripps Institution of Oceanography, La Jolla, California, during March 24-April 2, under the auspices of the International Union of Biological Sciences and jointly sponsored by the University of California and the Office of Naval Research of the United States Navy. Owing to generous financial help and to the co-operation of the Military Air Transport Service of the United States, a large and representative body of marine biologists attended from all parts of the world, eight being from Great Britain. The programme of prepared papers covered the whole range, and indeed more than is usually regarded as the whole range, of the composite science of marine biology. Certain of those invited to participate came to give accounts of work of very wide biological implication, and they also made major contributions to the discussions which followed the papers. Very adequate provision had been made in the time-table for such discussions.

It is undoubtedly true to say that no such broad survey of the field of biological investigation in the marine environment has hitherto been held. Observa. tion and discussion ranged from the factors of the marine environment to the study of bottom fauna and of plankton communities, through problems of biochemistry and regulation, both chemical and in respect of timing and rhythms, to problems of production and productivity, notably in relation to both phytoplankton and bacteria. The importance of ethology was stressed, and both the sensory equipment and effector mechanisms of marine organisms were discussed. Problems of speciation and of genetics formed the subject-matter of the concluding sessions of a programme that had bcen organized by Prof. A. A. Buzzati-Traverso, to whose distinction as a geneticist must certainly be added high ability as an organizer.

An experiment of great interest was made during the symposium, the participants in which were organized into a series of 'idea groups' of very mixed membership where the subject-matter of the papers and general matters appertaining to marine biology were informally discussed. 'The concluding session of the symposium took the form of a meeting at which spokesmen of the various groups gave some account of their deliberations and answered certain leading questions which had been put to thom. In the opinion of the writer, himself one of the spokesmen, profitable use could probably be made of such a scheme in future, although perhaps in this instance both subject-matter and participants were somewhat too heterogeneous. A doubt was left as to whether those who organized the symposium would obtain any major lead from the deliberations of the idea groups.

But there can be no doubt that, as a result of the discussions, both formal and informal, all who attended the symposium left it with increased knowledge both of their science and of their colleagues from many countries. Regret was widely expressed at the absence of the delegates expected from the U.S.S.R. The Scripps Institution of Oceanography now has the possibilities, through a major grant of money from the Rockefeller Foundation, to develop greatly the biological aspects of its work. Those responsible for the symposium must cortainly have gained an idea of the extent and diversity of modern investigations in marine biology. The majority of these, outside the field of fishery research, are the achievements of individual workers, although naturally such work is being increasingly aided by the facilities of modern marine biological laboratories and research vessels. Along what lines of research money might most fruitfully be spent would, at this stage, seem to depend more on the quality of the people employed than on the actual programme, and it is to be hoped that the Scripps Institution will be successful in its endeavours to obtain workers of the highest quality to develop its biological programme.

C. M. YoNGE

\section{SCIENTIFIC HUMANISM}

$I^{1}$ is a commonplace of discussions on the universities that there is an ever-widening gap between the arts and the science graduates: this usually takes the form of a most often unjust attack on the 'narrow scientist'. S. J. Tester, a lecturer in classics at the University of Bristol, suggests that the 'narrow arts graduate' is a commoner phenomenon and represents a more serious problem (Univ. Rev., 28, No. 2 ; Feb. 1956).

Most graduates in one of the special sciences will, in a time of films and theatres, radio and television, "Penguins" and "Pelicans", imbibe something of what the arts man so often describes as 'culture'; but most arts graduates leave the universities with practically no conception of the revolution that took place in science between the seventeenth and ninetcenth centuries, and the further revolutionary developments which have occurred since 1900. Unfortunately, they leave not feeling ashamed of this ignorance but either proud of it or indifferent to it; they consider it irrelevant to their being 'cultured' or 'educated'. Tester suggests a way in which both these problems-that of the science graduates' lack of contact with the minds of the great thinkers of the past and that of the arts graduates' blindness on the side of science--might be at least partly solved.

The way in which the universe in all its physical aspects is now regarded is largely due to develop. ments in science between the seventeenth and nineteonth centuries; it is to be expected that new developments in physics, physiology, psychology and electronics will produce changes in men's commonplace opinions in the future. It is possible to draw up a list of half a dozen or so books which would epitomize the 'scientific revolution', all, or nearly all, books written for the educated public of their day by men of generally acknowledged genius or importance, and all readable by any intelligent student. 